\title{
TEN RESTAURANTS
}

\section{THAT CHANGED AMERICA}

\author{
by Paul Freedman
}

\section{(A Book Review)}

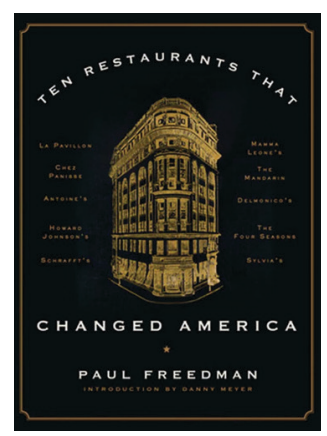

by Yale historian Paul Freedman to be the United States' first real restaurant. This 1838 menu is also the oldest in his book Ten Restaurants That Changed America, first published in 2016 and then in paperback in 2018. The galette, whose description sways from English to French and back to English, represents the book's most recent menu: a 2014 dinner at Chez Panisse in Berkeley, California. It serves as a snapshot of contemporary dining in America, where chefs free diners from an overwhelming number of choices and diners expect ingredients to be local.

In between these two meals, Freedman offers courses from eight other restaurants. There are huitres à la Rockefeller

1. Never shy of decadence, Oscar Wilde considered Delmonico's one of "the two most impressive sights in the United States" alongside Yosemite Valley (7-8).
L. Sasha Gora

Ludwig-Maximilians-

Universität

Munich

Germany

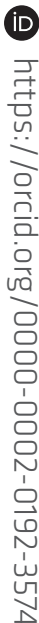


at Antoine's in New Orleans and club sandwiches at Schrafft's, also in New York. Or how about the fried clams at one of the 929 Howard Johnson's that dotted the United States in the1970s? There is also the iconic spaghetti with meatballs at New York's Mamma Leone's, or hot-and-sour soup at San Francisco's the Mandarin. Sylvia's in Harlem serves "down-home" fried or smothered chicken, and, further south in Manhattan, there's filet de sole au Chablis at Le Pavillon or salsify in wild game marinade at the Four Seasons. (Today, one can still book a table at Delmonico's, a successor of the original, as well as at Antoine's, Sylvia's, Chez Panisse, and, the recently relocated, Four Seasons.) Collapsing the nearly two centuries Paul Freedman covers, these are the ten restaurants, he argues, that changed America.

The title gives away the book's contents, but it is easy to overlook its most operative word: changed. Freedman writes about restaurants but tells a larger story. In tune with the interdisciplinary field of food studies, Freedman convincingly proves "food and cuisine reflect the culture at large" (433). Ten Restaurants That Changed America is an important contribution to an ever-growing body of literature that demonstrates how restaurants not only reflect social values but also construct them. Nestled between the public and the private, they are fascinating stages for cultural change.

This isn't a book about America's best restaurants. Instead,

Indigenous Social Movements in the Americas each chapter engages with larger social questions. With Schrafft's, Freedman touches on gendered access to public space and the history of restaurants opening their doors to women. The chapters on Mamma Leone's and the Mandarin both engage with socalled "ethnic" establishments and the potential of restaurants as gateways to experiencing other cultures. Sylvia's departs from the legacies of the Great Migration and reflects on eating out, race, and the civil rights movement. And the chapter on Howard Johnson's charts the history of franchising, frozen foods, and the emergence of roadside, middle-class family dining. Freedman based his selection on exemplary establishments-prototypes of sorts-that defined a category. One of the book's strengths is that it brings such different restaurants together in an effort to profile how the United States imagines itself through its meals. 
Many of the restaurants also clash and contradict one another. Delmonico's adhered to French gastronomy's rules but embraced American ingredients like terrapin (turtles) from Maryland (which Oscar Wilde once ordered). Regional distinction, present at Delmonico's and Antoine's, declined as Schrafft's and Howard Johnson's streamlined American classics. Le Pavillon promoted snobby French food, and, in contrast, The Four Seasons turned away from the French model and offered haute cuisine in an American accent. Alice Water's Chez Panisse is a reaction to assembly line food. Sylvia's, Schrafft's, and Howard Johnson's represent a culinary world many Americans could participate in, whereas, The Four Seasons charges prices that preserve its exclusivity.

Freedman treats the reader to many meals, but despite this range, an obvious critique is his narrow geographical scope. After all, seven of the ten restaurants were based (or at least present) in New York City. But there is perhaps a reason none of these restaurants are far from the coast. Freedman explains this was not intentional and yet these cities are all ports "and many of the influences on American food, from French food to immigration, passed through them" (xlv). In other words, Ten Restaurants celebrates immigrants. It documents migration and travel. Many of its characters arrived by boat or plane. Cecilia Chiang was born in Shanghai, and Henri Soulé was French. Immigrants also opened Delmonico's, Antoine's, and Mamma Leone's. For American-born Alice Waters, it was living in France where she learned to eat. Because of this, Freedman's ten restaurants are connected far beyond the country's borders.

In building up Chez Panisse's legacy of pioneering what many consider to be the beginning of contemporary American cuisine, Freedman writes: "All revolutions have to create a grim image of the past [...] against which they are revolting. Every 'Renaissance' has to manufacture its own 'Cothic' period or 'Dark Ages' [...]" (379). This also hints at Freedman's academic background. A professor of history at Yale, he is, in fact, a medievalist. Although his research has included the history of cuisine, especially the spice trade, and he edited Food: The History of Taste (2007), he specializes in medieval social history, with a focus on Catalonia. Keeping with the propri- 
etors and chefs he profiles, Ten Restaurants very much discusses American culinary history in dialogue with global shifts.

Continuing with the transatlantic, I included two chapters in my undergraduate food studies course at the University of Munich this past semester. Both were accessible in language, tone, and scope, to the students, all of who speak English as a second or even third language. Written with the light hand typical of journalism, the book also doubles as a gateway to thinking about menus as primary sources and how restaurants serve so much more than dinner.

Freedman also takes to heart the expression that we eat with our eyes. The book encompasses over 100 figures, ranging from menus to photographs (including an excellent one of "Henri Soulé inspecting a roast," in which his tightly pressed lips perfectly capture the brilliant yet bossy character Freedman describes), and from food-focused New Yorker covers to works of art, including Edward Hopper's 1929 Chop Suey. In addition to enticing students to read lengthy chapters, these figures all exemplify food's place in visual cultural studies. But Freedman doesn't only tease the reader with intriguing dishes. An appendix supplies "classic recipes," including Howard Johnson's famous fried clams and baked Alaska, invented at Delmonico's in 1867 in celebration of the Alaska purchase.

It is also fitting that the book begins in New York City and ends in California. In addition to its overarching question of what is

Indigenous Social Movements in the Americas American food, it casts a second story as its red thread: the fall of French cuisine's dominance. At first, it might seem ironic, then, that Ten Restaurants That Changed America both begins and ends with French restaurants, and yet somewhere along the way is the story of the coming-of-age of an American dining culture, in which the coasts were central.

I happen to be writing this in Berkeley. Chez Panisse is only a twenty-five minute walk northeast. But even closer is Café Ohlone. Run by Vincent Medina and Louis Trevino, the café uses pre-contact ingredients to cook creative dishes that serve an idea of how the Bay tasted before European colonization. Café Ohlone opened in 2018, and so it is not a contender for Freedman's list, and yet it points to an important absence. In Freedman's quest to study American restaurants, he overlooks Native American 
influences. Is it possible to discuss the reemergence of local and seasonal eating in the United States without considering Native Americans?

The book also dabbles in other absences. Although Freedman purposely tells a story that goes beyond McDonald's and fast food serving as the only definition of American food, I cannot help but think about salsa, smokers, and steak. A book about the ten dishes that changed America would look quite different from this one. Freedman reminds readers "there are more than 40,000 Chinese restaurants in the United States-more than there are branches of McDonald's, Burger King, and KFC combined" (209). But what about salsa-the nation's most popular condiment? ${ }^{2}$

Furthermore, his most recent example, Chez Panisse, opened in 1971, over two decades before The Food Network first aired in 1993 and represented a growing interest in not just eating but in talking about it, too. It was once considered un-American to fuss about food, and, today, in 2019, finding the best noodle bar or getting a reservation at a top restaurant has become a fully competitive American sport.

Keeping with a numbered approach, Freedman ends with five recent trends: farm-to-table; molecular/modernist gastronomy; celebrity chefs; the influence of Asia; and, the new informality of dining out. Despite this summary, I can't help but wonder how the book would read if it included a more recent contender, perhaps the likes of David Chang's Momofuko empire, which checks three of the five boxes. I wonder about these restaurants that defy categorization. Restaurants that go beyond national and regional cuisines, ones that-to borrow what was once the culinary world's "f-word,"-might be described as fusion, which Freedman only briefly touches upon. To call Chang's cooking fusion is not quite right, nor is it to call it "Asian" or "Asian-American." This would be ripe territory for considering what the late restaurant critic Jonathan Gold called "fusion from the other side" (Goldstein 316).

Ten Restaurants That Changed America gifts readers a handful of facts fun enough for a dinner party (like that the term "power lunch" was coined in a 1979 Esquire article to describe well-heeled

2. Salsa sales overtook ketchup in 1991 (Pilcher 673). 
lunches at the Four Seasons), but it also does more important work. For those who are new to food studies, Ten Restaurants That Changed America solidifies that eating out is an important part of popular culture. It further exemplifies the importance of historicizing what has become naturalized: the now ordinary act of going out for dinner. Furthermore, from convenience to exclusivity and from forty veal dishes to a menu that presents no options at all, the book documents the continual evolution of an insatiable American appetite. 
Freedman, Paul. Ten Restaurants That Changed America. Liveright, 2016.

Goldstein, Joyce. Inside the California Food Revolution: Thirty Years That Changed Our Culinary Consciousness. U of California P, 2013.

Pilcher, Jeffrey M. "Tex-Mex, Cal-Mex, New Mex, or Whose Mex? Notes on the Historical Geography of Southwestern Cuisine." Journal of the Southwest, vol. 43, no. 4, Winter 2001, pp. 659679. JSTOR, https://www.jstor.org/stable/pdf/40170174. pdf?seq=1\#page_scan_tab_contents.

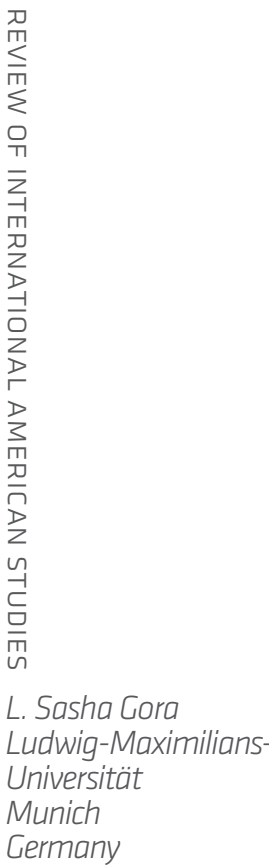


